\title{
Derivation of hepato-pancreatic intermediate progenitor cells from a clonal mesenchymal stem cell line of rat bone marrow origin
}

\author{
TAKURO MASAKA ${ }^{1,2}$, MASAHIRO MIYAZAKI ${ }^{1,3}$, GANG DU $^{1}$, MARHAEN HARDJO ${ }^{1,4}$, \\ MASAKIYO SAKAGUCHI ${ }^{1}$, MIKIRO TAKAISHI ${ }^{1}$, KEN KATAOKA ${ }^{1}$, \\ KAZUHIDE YAMAMOTO ${ }^{2}$ and NAM-HO HUH $^{1}$
}

\begin{abstract}
${ }^{1}$ Departments of Cell Biology, ${ }^{2}$ Gastroenterology and Hepatology, Okayama University Graduate School of Medicine, Dentistry and Pharmaceutical Sciences, Shikata-Chou, Okayama; ${ }^{3}$ Department of Food and Nutrition, Faculty of Human Services, Okayama Gakuin University, Aruki, Kurashiki, Japan; ${ }^{4}$ Department of Biochemistry, Faculty of Medicine, Hasanuddin University, Makassar, South Sulawesi, Indonesia
\end{abstract}

Received May 29, 2008; Accepted July 21, 2008

DOI: 10.3892/ijmm_00000041

\begin{abstract}
We have recently established a clonal mesenchymal stem cell line (rBM25/S3) from adult rat bone marrow. The cells have practically unlimited proliferation capacity (over 300 PDL), maintaining multipotency for differentiation. In the present study, we examined the potential for $\mathrm{rBM} 25 / \mathrm{S} 3$ cells to differentiate into insulin-secreting cells. When cultured in the presence of HGF and FGF-4 on Matrigel, rBM25/S3 cells expressed genes specific to pancreatic $\beta$-cells as well as those specific to hepatocytes. They still maintained proliferation capacity with a doubling time of $\sim 30 \mathrm{~h}$. These hepato-pancreatic intermediate progenitor cells, but not the original undifferentiated $\mathrm{rBM} 25 / \mathrm{S} 3$ cells, were induced by the overexpression of PDX-1 to produce significant amounts of insulin in a manner responding to glucose concentration in medium. The present culture system indicates a direction for further studies aimed at the realization of cell transplantation therapy for type I diabetes mellitus.
\end{abstract}

\section{Introduction}

Type I diabetes is a disorder characterized by autoimmunemediated destruction of insulin-producing $\beta$-cells in the pancreas. Islet cell transplantation is a promising strategy for treatment of this disease (1), but its application is limited by the shortage of donor pancreata. Therefore, development of a

Correspondence to: Dr N. Huh, Department of Cell Biology, Okayama University Graduate School of Medicine, Dentistry and Pharmaceutical Sciences, 2-5-1 Shikata-cho, Okayama 700-8558, Japan

E-mail: namu@md.okayama-u.ac.jp

Key words: mesenchymal stem cells, insulin, PDX-1, progenitor cells, albumin cell source for supplying a large quantity of insulin-producing cells is a prerequisite for successful cell therapy. In this respect, stem cells have been attracting much attention due to the high proliferation potential and multiple differentiation potency, including differentiation into pancreatic B-cell lineage (2-7). Due to its easy accessibility, the bone marrow would be the most suitable source of stem cells for practical application if the efficiency of differentiation into insulin-producing cells is sufficiently high $(6,7)$.

In normal embryonic development, the liver and pancreas share common precursor cells. In accordance with this, it has been reported that hepatic stem cells (8), fetal liver cells $(9,10)$, and adult hepatocytes $(11)$ can be converted or transdifferentiated into insulin-producing cells. Yang et al (5) demonstrated that highly purified rat hepatic oval cells, when cultured in a high-glucose environment, can trans-differentiate into functional insulin-producing cells. Since the conditions for bone marrow-derived stem cells to differentiate into hepatocyte-like cells have been well established $(12,13)$, it may be efficient to induce $\beta$-cells via hepatogenic progenitor cells or common precursor cells.

We recently established a clonal mesenchymal stem cell line (rBM25/S3) from adult rat bone marrow (14). The cells grew rapidly (doubling time, $\sim 24 \mathrm{~h}$ ) over 300 population doubling levels (PDLs), maintaining the normal diploid karyotype and multipotency for differentiation. rBM25/S3 cells can be induced to differentiate into hepatocyte-like cells with an extremely high efficiency, i.e., almost $100 \%$ of the cells expressed albumin and other hepatocyte-specific markers within 5 days when cultured in the presence of HGF and FGF-4 on Matrigel. In the present study, we compared original $\mathrm{rBM} 25 / \mathrm{S} 3$ cells with the hepatogenic derivatives in terms of $\beta$-cell-specific gene expression by the overexpression of PDX-1. PDX-1 (pancreatic and duodenal homeobox gene 1) is a major pancreatic fate-determining transcription factor (15). Ferber et al (16) found that ectopic expression of PDX-1 induced insulin in the liver of mice. We found that the hepatogenic derivatives of $\mathrm{rBM} 25 / \mathrm{S} 3$ were induced to 
produce insulin by overexpressed PDX-1 at a much higher level than that produced by the original undifferentiated clone.

\section{Materials and methods}

Cytokines, matrix proteins and enzymes. Epidermal growth factor (EGF), platelet-derived growth factor (PDGF)-BB (Sigma-Aldrich, St. Louis, MO), and fibroblast growth factor (FGF)-4 (R\&D Systems, Minneapolis, MN) were commercially obtained. HGF ( $\Delta 5$ variant, a mature two-chain form: 17 ) was kindly provided by Daiichi Pharmaceutical (Tokyo, Japan). Fibronectin and Matrigel were purchased from Sigma-Aldrich and BD Sciences (Bedford, MA), respectively. Type I collagen was prepared from rat-tail tendon as described previously (13). Trypsin (1:250) was purchased from Difco Laboratories (Detroit, MI).

Cell culture. $\mathrm{rBM} 25 / \mathrm{S} 3$ cells (14) were maintained in fibronectin $\left(1 \mu \mathrm{g} / \mathrm{cm}^{2}\right)$-coated dishes containing multipotent adult progenitor cell (MAPC) medium supplemented with 2\% FBS, pyruvate $(0.11 \mathrm{mg} / \mathrm{ml})$, EGF $(10 \mathrm{ng} / \mathrm{ml})$ and PDGF-BB $(10 \mathrm{ng} / \mathrm{ml})$. Thereafter, cells were continuously subcultured at an interval of 3 or 4 days. For the induction of hepatocytelike cells, rBM25/S3 cells were inoculated into 1\% Matrigelcoated dishes containing MAPC medium supplemented with HGF (20 ng/ml) and FGF-4 (10 ng/ml) and cultured for 4-7 days (14).

Immunostaining of cells. Cultured cells were fixed with $4 \%$ paraformaldehyde and treated with an anti-human albumin (Dako, Denmark), anti-synthetic peptide corresponding to the carboxy-terminal of mouse/rat PDX-1 (Chemikon), anti-swine insulin (Dako, Denmark) or anti-rat C-peptide antibody (Linco Research) followed by a TRITC- (Sigma), Cy2- or Cy3conjugated second antibody (Amersham Bioscience). The samples were mounted with Vectashield (Vector Laboratories, Burlingame, CA) and observed under a confocal laser scanning microscope (LSM510; Carl Zeiss) or a fluorescence microscope (Olympus).

$R T$-PCR. Total RNA was extracted from cells using TRI Reagent (Sigma) and pretreated with DNase I (Invitrogen). cDNA was synthesized from $5 \mu \mathrm{g}$ of RNA samples with SuperScript II RNaseH-reverse transcriptase (Invitrogen) and amplified under the following conditions: initial incubation at $94^{\circ} \mathrm{C}$ for $4 \mathrm{~min}$ followed by 30 cycles at $94^{\circ} \mathrm{C}$ for $30 \mathrm{sec}$, $55^{\circ} \mathrm{C}$ for $30 \mathrm{sec}, 72^{\circ} \mathrm{C}$ for $30 \mathrm{sec}$, and then a final step at $72^{\circ} \mathrm{C}$ for $5 \mathrm{~min}$. Samples without reverse transcription were used as a negative control. The primers and expected lengths of products were as follows: (albumin), $503 \mathrm{bp}$, sense strand: 5'-gacaacatt cctgccgatct-3', antisense strand: 5'-agcacacacagacggttcag-3'; (insulin 1), $331 \mathrm{bp}$, sense strand: 5'-atggccetgtggatgcgctt-3', antisense strand: 5'-tagttgcagtagttctccagct-3'; (insulin 2), 245 bp, sense strand: 5-atggccctgtggatccgctt-3, antisense strand: 5'-tgccaaggtctgaaggtcac-3'; [glucose transporter 2 (GLUT-2)], 345 bp, sense strand: 5'-ttagcaactgggtctgcaat-3', antisense strand: 5'-ggtgtagtcctacactcatg-3'; [glyceraldehyde-3phosphate-dehydrogenase (GAPDH)], $440 \mathrm{bp}$, sense strand: 5'-atgggaagctggtcatcaac-3', antisense strand: 5'-ggatgcaggg atgatgttct-3'. GAPDH was used as an internal control. The amplified products were subjected to electrophoresis in $1.5 \%$ agarose gels and stained with ethidium bromide.

Adenovirus constructs. An adenovirus vector carrying human PDX-1 gene (Ad-PDX-1) was prepared by using BD Adeno-X Expression System 2 (BD Biosciences) under the conditions recommended by the manufacturer. An adenovirus vector carrying LacZ gene (Ad-LacZ) was similarly prepared and used as a negative control.

Quantitation of insulin secreted into the medium. Cells were plated at $2.5 \times 10^{3}$ cells $/ \mathrm{cm}^{2}$ in 24 -well plates and cultured for 7 days. After washing with phosphate-buffered saline, cells were pre-incubated for $30 \mathrm{~min}$ in a glucose-free Krebs-Ringer bicarbonate (KRB) buffer (Sigma) and then incubated in the same buffer supplemented with $10 \mathrm{mM}$ or $25 \mathrm{mM}$ glucose for $1 \mathrm{~h}$. A concentration of insulin secreted into the buffer solution was measured using an ELISA kit for rat insulin (Shibayagi, Gumma, Japan).

Statistical analysis. All experiments were repeated a minimum of three times independently, and the results were expressed as a mean \pm SD. Statistical difference was determined by the unpaired Student's t-test, and $\mathrm{p} \leq 0.05$ was considered statistically significant.

\section{Results}

We previously established a clonal cell line (rBM25/S3) from rat bone marrow (14). The cells, small and asteroid in shape (Fig. 1A-1), were maintained in the presence of EGF and PDGF-BB on a fibronectin substratum. When cultured with HGF (20 ng/ml) and FGF-4 (10 ng/ml) on Matrigel, rBM25/S3 cells efficiently $(\sim 100 \%)$ differentiated within 7 days into hepatocyte-like cells that expressed albumin (Fig. 1A-2,-3). By using RT-PCR analysis, albumin mRNA was detected as early as day 4 and increased until day 7 (Fig. 1B). In addition, these cells were shown in our previous study (14) to express $\alpha$-fetoprotein (AFP), glucose-6-phosphatase (G6Pase), triptophan-2,3-dioxygenase (TO), tyrosine amino-transferase (TAT), cytochrome P450 (CYP)1A1, CYP1A2, cytokeratin (CK)-8 and CK-18.

We examined the growth of the differentiated $\mathrm{rBM} 25 / \mathrm{S} 3$ cells for $\geq 7$ days, the observation period in our previous study (14). As shown in Fig. 2, rBM25/S3 cells, under the conditions for hepatogenic differentiation, grew continuously over a period of 60 days with a doubling time of $30.8 \mathrm{~h}$, indicating that the differentiated rBM25/S3 cells retained stable growth capacity, though at a lower rate than that of the undifferentiated cells (doubling time: $17.5 \mathrm{~h}$ ). Since stem cells generally lose their proliferation capacity when induced to fully differentiate, we assumed that the differentiated $\mathrm{rBM} 25 / \mathrm{S} 3$ cells, under the conditions described previously, were not terminallydifferentiated hepatocytes but were at an intermediate stage. This was verified by the results of the experiment, shown in Fig. 3, in which the expression of insulin 1 and GLUT-2 was detected in the differentiated $\mathrm{rBM} 25 / \mathrm{S} 3$ cells but not in the undifferentiated $\mathrm{rBM} 25 / \mathrm{S} 3$ cells.

Since PDX-1 is known to play a crucial role in inducing differentiation and maintaining the function of $\beta$-cells $(15,18)$, 
A
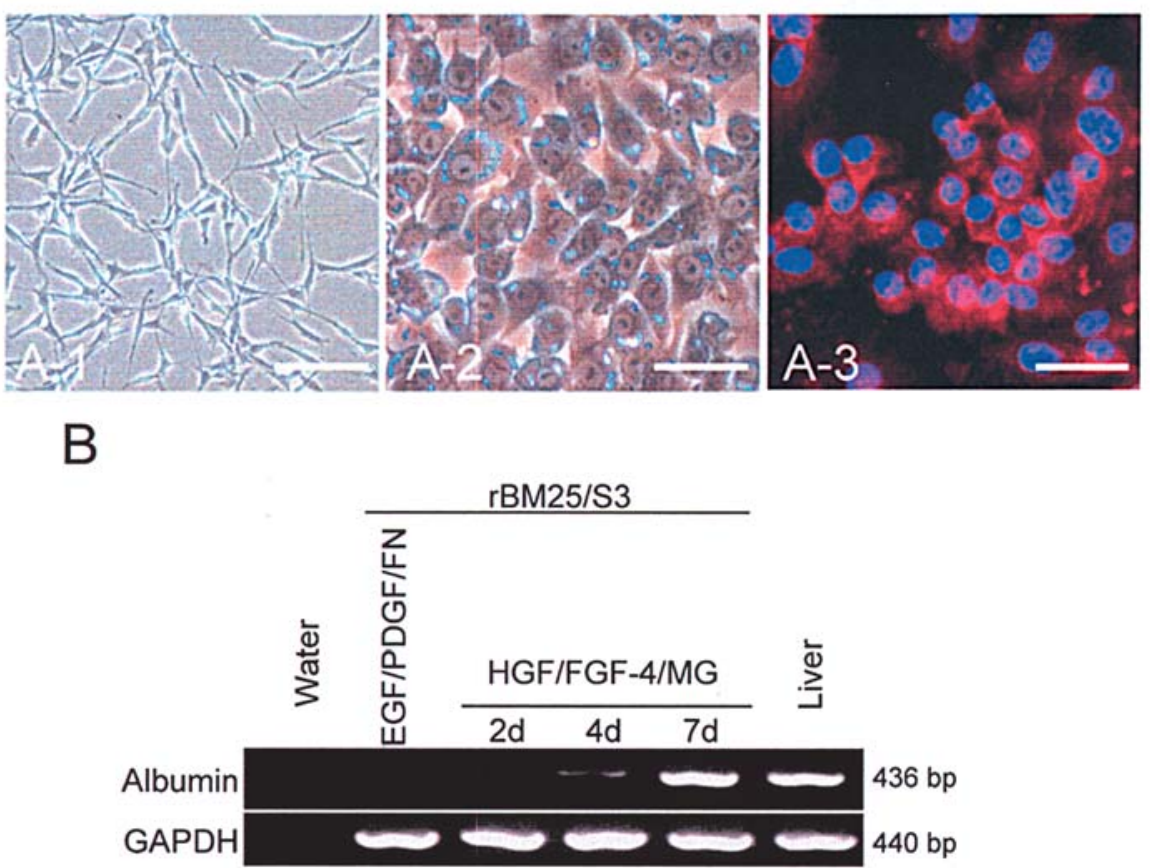

Figure 1. Differentiation of rBM25/S3 cells into hepatocyte-like cells in vitro. (A-1) Morphology of rBM25/S3 cells cultured under conditions for maintenance propagation, i.e., in the presence of EGF (10 ng/ml) and PDGF-BB (10 ng/ml) on fibronectin (EGF/PDGF/FN). (A-2) Hepatogenic differentiation of rBM25/S3 cells cultured for 7 days on Matrigel with HGF (20 ng/ml) and FGF-4 (10 ng/ml) (HGF/FGF-4/MG). (A-3) Immunostaining for albumin in the cells shown in A-2. Scale bars, $50 \mu \mathrm{m}$. (B) RT-PCR for albumin mRNA. rBM25/S3 cells cultured under designated conditions. d, days. GAPDH was used to present applied amounts of the samples.

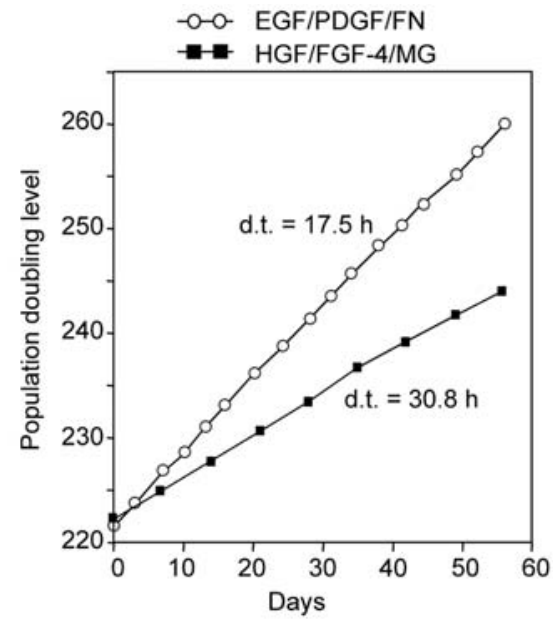

Figure 2. Growth curves and the hepatogenically differentiated derivative of rBM25/S3 cells. rBM25/S3 cells were transferred at 224.7 PDL into culture conditions for differentiation, i.e., on Matrigel with HGF $(20 \mathrm{ng} / \mathrm{ml})$ and FGF-4 (10 ng/ml). d.t., doubling time.

we examined the effect of overexpression of the PDX-1 gene in undifferentiated and differentiated $\mathrm{rBM} 25 / \mathrm{S} 3$ cells. Infection of Ad-PDX-1 two days prior to harvest induced the differentiated $\mathrm{rBM} 25 / \mathrm{S} 3$ cells to express insulin 2 in addition to insulin 1 and GLUT-2 (Fig. 3). In contrast, the undifferentiated $\mathrm{rBM} 25 / \mathrm{S} 3$ cells expressed no $B$-cell-specific genes even after infection with Ad-PDX-1. Immunostaining demonstrated that insulin protein was present at a detectable

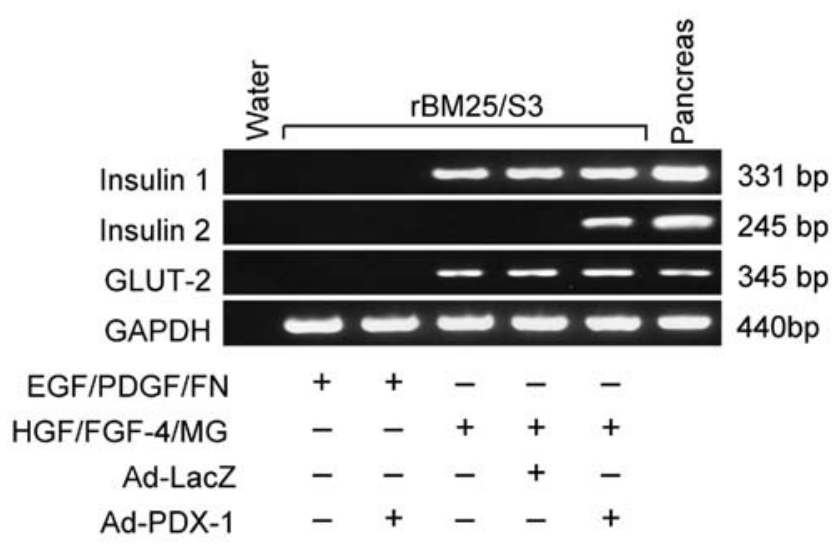

Figure 3. Expression of $\beta$-cell-specific genes in differentiated $\mathrm{rBM} 25 / \mathrm{S} 3$ cells and effect of over-expression of PDX-1. RT-PCR for rat insulin 1, insulin 2 and GLUT-2 mRNAs. rBM25 cells were cultured under designated conditions (Fig. legend 1) for 7 days. An adenovirus carrying LacZ (AdLacZ) or PDX-1 (Ad-PDX-1) was infected at 10 MOI two days before harvest. Water and mRNA from rat pancreas were used as negative and positive controls.

level in the cytoplasm of PDX-1-positive rBM25/S3 cells cultured under the differentiation conditions but not in AdLacZ-infected cells (Fig. 4A). All of the insulin-positive cells were also stained for PDX-1, which localized in the nuclei. Under similar conditions, C-peptide was detected in PDX-1positive rBM25/S3 cells (Fig. 4B). This observation excluded the possibility that insulin protein shown in Fig. A-5 was of exogenous origin taken up from the medium. 


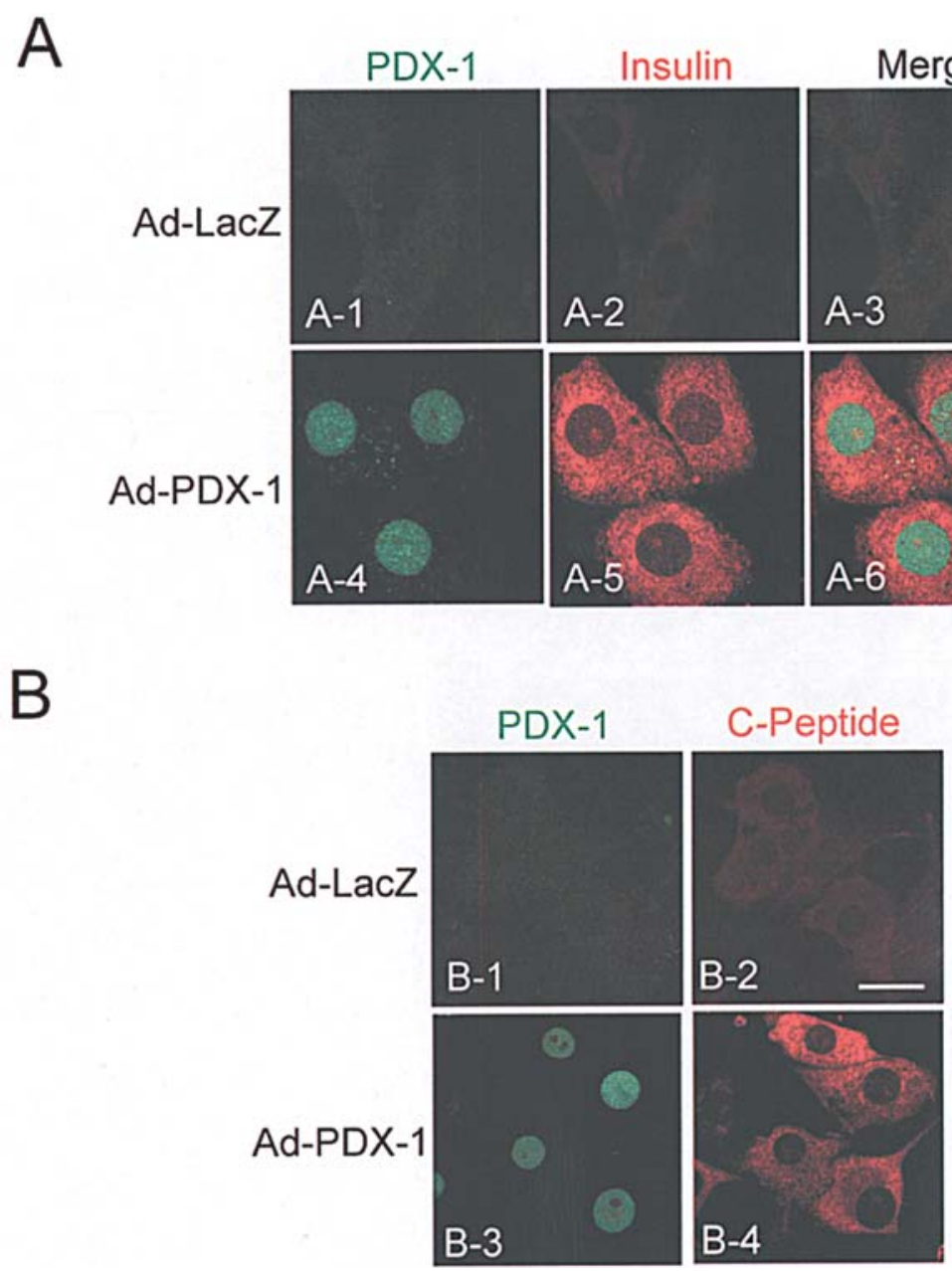

Figure 4. Expression of insulin and C-peptide in differentiated rBM25/S3 cells transduced with PDX-1 using an adenovirus. rBM25/S3 cells were cultivated in the presence of HGF (20 ng/ml) and FGF-4 (10 ng/ml) on Matrigel for 7 days. Ad-PDX-1 was applied on culture day 5. (A) Immunostaining for PDX-1 (in green) and insulin (in red) in the differentiated rBM25/S3 cells without (panels A-1 to 3) or with (panels A-4 to 6) overexpression of PDX-1. Scale bar (20 $\mu \mathrm{m}$ ) is applicable to all panels. (B) Immunostaining for PDX-1 (in green) and C-peptide (in red) in differentiated rBM25/S3 cells without (panels B-1,2) or with (panels B-3,4) overexpression of PDX-1. Scale bar $(20 \mu \mathrm{m})$ is applicable to all panels.

A

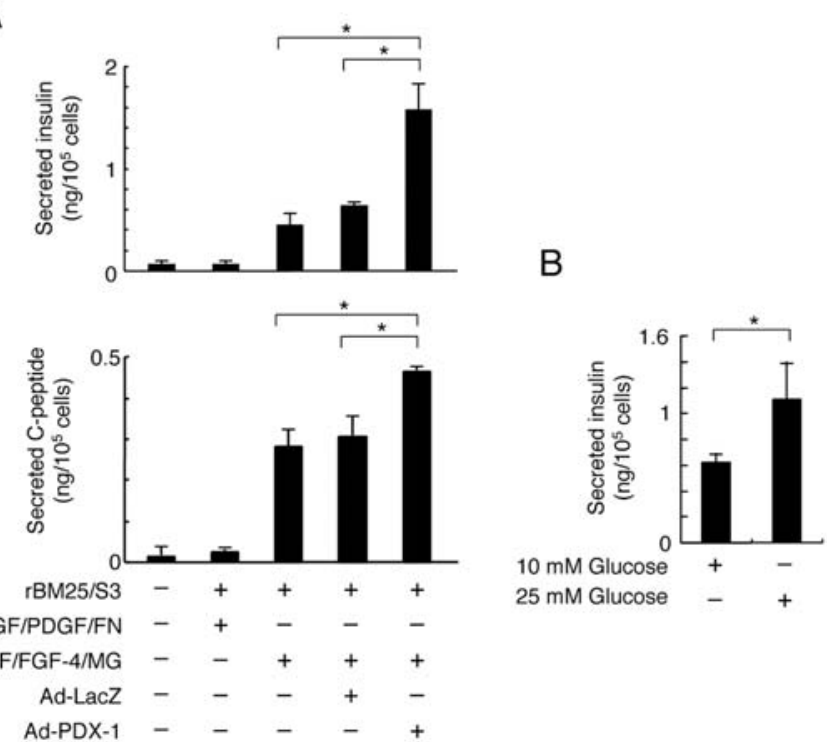

Figure 5. Quantification of secreted insulin (A upper panel, B) and C-peptide (A lower panel) by ELISA. (A) rBM25/S3 cells were induced to differentiate under conditions described in Fig. legend 4. Ad-LacZ was used as a control. On culture day 7, the cells were incubated for $1 \mathrm{~h}$ in KRB buffer with $25 \mathrm{mM}$ glucose and the proteins in the buffer were determined by ELISA. (B) The effects of glucose concentration in the incubation buffer on insulin secretion by $\mathrm{rBM} 25 / \mathrm{S} 3$ cells that were cultured under differentiation conditions (HGF/FGF-4/MG) and infected with Ad-PDX-1.

Finally, we quantitated the amounts of insulin and C-peptide secreted by $\mathrm{rBM} 25 / \mathrm{S} 3$ cells into the medium (Fig. 5). Undifferentiated $\mathrm{rBM} 25 / \mathrm{S} 3$ cells secreted no significant

amounts of insulin or C-peptide, while the differentiated cells cultured with HGF and FGF-4 on Matrigel secreted remarkable amounts of the two proteins, $\sim 0.4 \mathrm{ng} / 10^{5}$ cells $/ \mathrm{h}$ insulin and 
$\sim 0.3 \mathrm{ng} / 10^{5}$ cells $/ \mathrm{h}$ C-peptide (Fig. 5A). Infection of the differentiated cells with Ad-PDX-1 further increased the secreted amounts of insulin and C-peptide, $\sim 1.6 \mathrm{ng} / 10^{5} \mathrm{cells} / \mathrm{h}$ insulin and $\sim 0.45 \mathrm{ng} / 10^{5}$ cells/h C-peptide. The Ad-PDX-1infected differentiated $\mathrm{rBM} 25 / \mathrm{S} 3$ cells were responsive to glucose concentration in the incubation buffer, i.e., $\sim 2$-fold larger amount of insulin was secreted into the buffer at $25 \mathrm{mM}$ glucose than that at $10 \mathrm{mM}$ glucose (Fig. 5B).

\section{Discussion}

As previously reported (14), rBM25/S3 cells isolated from rat bone marrow express CD29, CD44, CD49b, CD90, vimentin and fibronectin but not CD45, indicating that they are of mesenchymal cell origin. When cultured in the presence of HGF and FGF-4 on Matrigel, the cells expressed AFP, albumin, CYP1A1, CYP1A2, G6Pase, TO, TAT, CK-8, and CK-18. The differentiated cells, when intrasplenically transplanted, prevented otherwise fatal liver failure in 90\% hepatectomized rats. From the above results, we assumed rBM25/S3 cells cultured with HGF and FGF-4 on Matrigel to be hepatocyte-like cells. In the present study, however, it was evident that the differentiated $\mathrm{rBM} 25 / \mathrm{S} 3$ cells still retained stable proliferation capacity over 60 days with a doubling time of 30.8 h (Fig. 2). In addition, the cells expressed genes specific to pancreatic $\beta$-cells such as insulin 1 and GLUT-2 (Fig. 3). GLUT-2 is known to be expressed also in hepatocytes. It is probably more appropriate, therefore, to regard the rBM25/S3 cells differentiated with HGF and FGF-4 on Matrigel as hepato-pancreatic intermediate progenitor cells.

The homeodomain transcription factor, PDX-1, is a key regulator of pancreatic development and insulin expression in B-cells $(15,16)$. Although expression of insulin 1 and GLUT-2 was demonstrated in the differentiated $\mathrm{rBM} 25 / \mathrm{S} 3$ cells by RT-PCR (Fig. 3), insulin protein was undetectable by immunostaining and no significant secretion of insulin was observed (Figs. 4 and 5). This indicates that the functional level of the differentiated $\mathrm{rBM} 25 / \mathrm{S} 3$ cells as $\beta$-cells was extremely low. Adenovirus-mediated transfer of PDX-1 induced expression of insulin 2 mRNA and remarkable production of insulin in the differentiated $\mathrm{rBM} 25 / \mathrm{S} 3$ cells. It should be noted that Ad-PDX-1 can not induce any B-cellspecific gene expression in the undifferentiated $\mathrm{rBM} 25 / \mathrm{S} 3$ cells (Fig. 3).

The liver and pancreas are closely related organs in embryonic development. Highly purified adult rat hepatic oval cells, which are capable of differentiating into hepatocytes and biliary ductal cells, were shown to also differentiate into insulin-producing cells when cultured in a high-glucose environment (5). Nakajima-Nagata et al (19) showed that forced expression of mouse PDX-1 induced insulin production as well as the expression of endogenous rat PDX-1 and insulin 2 mRNA in small hepatocytes derived from adult rat liver. Oval cells were indicated to be of bone marrow origin (20). rBM25/S3 cells differentiated with HGF and FGF-4 on Matrigel may correspond to oval cells that are observed in the liver.

Stem cell-based therapy is a promising strategy for treating insulin-dependent diabetes mellitus because of the serious shortage of donor pancreata or isolated pancreatic islets for transplantation. Previously, Oh et al (21) showed that insulin-secreting cells trans-differentiated from bone marrow cells can maintain serum glucose level, upon subcapsular renal transplantation into hyperglycemic mice, for 90 days. However, the availability of highly functional cells in large quantities remains a major challenge. $\mathrm{rBM} 25 / \mathrm{S} 3$ cells have the following properties: 1) they grow rapidly with a doubling time of $\sim 24 \mathrm{~h}$ at least until PDL 300,2) they stably retain cellular phenotypes including the diploid karyotype, 3) they differentiate into hepatocyte-like cells (or hepato-pancreatic progenitor cells as indicated in the present study) at practically $100 \%$ efficiency within one week (1), and 4) the induced hepatocyte-like cells produce insulin according to adenovirusmediated transfer of PDX-1. Thus, the present culture system indicates a direction for further studies aimed at the realization of cell transplantation therapy for type I diabetes mellitus.

\section{Acknowledgements}

This work was partly supported by a grant from the Japanese Ministry of Education, Culture, Sports, Science and Technology (18590269).

\section{References}

1. Shapiro AM, Lakey JR, Ryan EA, Korbutt GS, Toth E, Warnock GL, Kneteman NM and Rajotte RV: Islet transplantation in seven patients with type 1 diabetes mellitus using a glucocorticoid-free immunosuppressive regimen. N Engl J Med 343: 230-238, 2000.

2. Seissler J and Schott M: Generation of insulin-producing $\beta$ cells from stem cells-perspectives for cell therapy in type 1 diabetes. Horm Metab Res 40: 155-161, 2008.

3. Lumelsky N, Blondel O, Laeng P, Velasco I, Ravin R and McKay R: Differentiation of embryonic stem cells to insulinsecreting structures similar to pancreatic islets. Science 292: 1389-1394, 2001

4. Zulewski H, Abraham EJ, Gerlach MJ, Daniel PB, Moritz W, Muller B, Vallejo M, Thomas MK and Habener JF: Multipotential nestin-positive stem cells isolated from adult pancreatic islets differentiate ex vivo into pancreatic endocrine, exocrine, and hepatic phenotypes. Diabetes 50: 521-533, 2001.

5. Yang L, Li S, Hatch H, Ahrens K, Cornelius JG, Petersen BE and Peck AB: In vitro trans-differentiation of adult hepatic stem cells into pancreatic endocrine hormone-producing cells. Proc Natl Acad Sci USA 99: 8078-8083, 2002.

6. Moriscot C, de Fraipont F, Richard MJ, Marchand M, Savatier P, Bosco D, Favrot $\mathrm{M}$ and Benhamou PY: Human bone marrow mesenchymal stem cells can express insulin and key transcription factors of the endocrine pancreas developmental pathway upon genetic and/or microenvironmental manipulation in vitro. Stem Cells 23: 594-603, 2005.

7. Karnieli O, Izhar-Prato Y, Bulvik S and Efrat S: Generation of insulin-producing cells from human bone marrow mesenchymal stem cells by genetic manipulation. Stem Cells 25: 2837-2844, 2007.

8. Tang DQ, Lu S, Sun YP, Rodrigues E, Chou W, Yang C, Cao LZ, Chang LJ and Yang LJ: Reprogramming liver-stem WB cells into functional insulin-producing cells by persistent expression of Pdx1- and Pdx1-VP16 mediated by lentiviral vectors. Lab Invest 86: 83-93, 2006.

9. Zalzman M, Gupta S, Giri RK, Berkovich I, Sappal BS, Karnieli O, Zern MA, Fleischer N and Efrat S: Reversal of hyperglycemia in mice by using human expandable insulin-producing cells differentiated from fetal liver progenitor cells. Proc Natl Acad Sci USA 100: 7253-7258, 2003.

10. Zalzman M, Anker-Kitai L and Efrat S: Differentiation of human liver-derived, insulin-producing cells toward the $B$-cell phenotype. Diabetes 54: 2568-2575, 2005.

11. Sapir T, Shternhall K, Meivar-Levy I, Blumenfeld T, Cohen H, Skutelsky E, Eventov-Friedman S, Barshack I, Goldberg I, Pri-Chen S, Ben-Dor L, Polak-Charcon S, Karasik A, Shimon I, Mor E and Ferber S: Cell-replacement therapy for diabetes: Generating functional insulin-producing tissue from adult human liver cells. Proc Natl Acad Sci USA 102: 7964-7969, 2005. 
12. Schwartz RE, Reyes M, Koodie L, Jiang Y, Blackstad M, Lund T, Lenvik T, Johnson S, Hu WS and Verfaillie CM: Multipotent adult progenitor cells from bone marrow differentiate into functional hepatocyte-like cells. J Clin Invest 109: 1291-1302, 2002.

13. Miyazaki M, Akiyama I, Sakaguchi M, Nakashima E, Okada M, Kataoka $\mathrm{K}$ and Huh NH: Improved conditions to induce hepatocytes from rat bone marrow cells in culture. Biochem Biophys Res Commun 298: 24-30, 2002.

14. Miyazaki M, Hardjo M, Masaka T, Tomiyama K, Mahmut N, Medina RJ, Niida A, Sonegawa H, Du G, Yong R, Takaishi M, Sakaguchi M and Huh NH: Isolation of a bone marrow-derived stem cell line with high proliferation potential and its application for preventing acute fatal liver failure. Stem Cells 25: 2855-2863, 2007.

15. Jonsson J, Carlsson L, Edlund T and Edlund H: Insulinpromoter-factor 1 is required for pancreas development in mice. Nature 371: 606-609, 1994.

16. Ferber S, Halkin A, Cohen H, Ber I, Einav Y, Goldberg I, Barshack I, Seijffers R, Kopolovic J, Kaiser N and Karasik A: Pancreatic and duodenal homeobox gene 1 induces expression of insulin genes in liver and ameliorates streptozotocin-induced hyperglycemia. Nat Med 6: 568-572, 2000.
17. Shima N, Tsuda E, Goto M, Yano K, Hayasaka H, Ueda M and Higashio K: Hepatocyte growth factor and its variant with a deletion of five amino acids are distinguishable in their biological activity and tertiary structure. Biochem Biophys Res Commun 200: 808-815, 1994.

18. Melloul D: Transcription factors in islet development and physiology: role of PDX-1 in beta-cell function. Ann N Y Acad Sci 1014: 28-37, 2004.

19. Nakajima-Nagata N, Sakurai T, Mitaka T, Katakai T, Yamato E, Miyazaki J, Tabata Y, Sugai M and Shimizu A: In vitro induction of adult hepatic progenitor cells into insulinproducing cells. Biochem Biophys Res Commun 318: 625-630, 2004.

20. Petersen BE, Bowen WC, Patrene KD, Mars WM, Sullivan AK, Murase N, Boggs SS, Greenberger JS and Goff JP: Bone marrow as a potential source of hepatic oval cells. Science 284: $1168-1170,1999$

21. Oh SH, Muzzonigro TM, Bae SH, LaPlante JM, Hatch HM and Petersen BE: Adult bone marrow-derived cells transdifferentiating into insulin-producing cells for the treatment of type I diabetes. Lab Invest 84: 607-617, 2004. 